\title{
Centre for Neuroscience: An Exploration of Signalling in Neural Development, Health and Disease
}

The Centre for Neuroscience was established in 1999 within the Faculty of Medicine, Dentistry and Health Sciences at the University of Melbourne, Australia. It was created to provide a strategic focus for neuroscience research within the University of Melbourne and to build on a strong and established research base. The Centre acts as a hub to bring together the breadth of neuroscience excellence in the Parkville precinct, to address a variety of problems within the broad field of neuroscience. One of the main underlying themes of research within the core group of researchers at the Centre is based on gaining an understanding of the signal transduction processes regulating neural development and neural cell function in health and disease, with the ultimate aim of translating this knowledge into therapeutic strategies. Some of these research areas are highlighted in this series of reviews, which are largely focussed on understanding of signalling pathways involved in promoting neural regeneration. However, it is clear that mechanisms that result in neural degeneration, via disease or injury, also need to be understood if regenerative efforts are to succeed and this is addressed in several of the articles.

The first three reviews are focussed on signals that regulate neural stem/progenitor cells. The first, by Denham and Dottori, describes the current state of knowledge regarding the general specification of neural differentiation and specific neural cell fates of human ES cells. This is followed by an examination of the role of lysophospholipids in regulating neural differentiation by Pitson and Pébay, which compares and contrasts the different effects of these molecules in mouse and human stem and neural progenitor cells. The third is from the Cate laboratory, on the role of BMP signalling in the regulation of adult neural precursor cells and the influence that BMPs may have on neural precursor function following CNS injury. This is followed by four articles on factors regulating mature neural cell function. The importance of neurotrophin and TAM receptor signalling in regulating myelin development and myelin breakdown, respectively, are highlighted in comprehensive reviews from the Murray and Kilpatrick laboratories. The next two reviews are focussed on neurons. The first, by Cole, examines what little is currently known about the PCTAIRE kinases and their probably important roles in neuronal function, highlighting areas that need to be addressed and proposing ways in which this might be done. This is followed by a review from Scarr, providing an overview of what is known about the role of muscarinic receptors, their potential to be targeted in psychiatric disorders and the gaps in knowledge that need to be filled. The final review, by Munro and Perreau, highlights the complexities of performing microarrays for transcriptional profiling of the nervous system and describes current and emerging applications for this technology, with specific reference to gene regulation following CNS disease and injury. It also provides an experimental design flow chart to help researchers contemplating using transcriptomics to navigate and design their own projects.

What is clear from this series is that we still have a long way to go before we will understand the many complex and interacting pathways that regulate nervous system function, not only under normal conditions, but also under the even more complex and challenging conditions that arise following CNS injury or disease. It is hoped that this snapshot of some of the research being undertaken in these areas within the Centre for Neuroscience will provide a useful and thought-provoking resource for those with an interest in signalling pathways modulating neural cell function in the healthy and the damaged CNS. Ann Turnley (The University of Melbourne)

\section{KARGER}

Fax +4161306 1234 E-Mail karger@karger.ch www.karger.com
(C) 2009 S. Karger AG, Basel

$1424-862 X / 09 / 0174-0233 \$ 26.00 / 0$

Accessible online at:

www.karger.com/nsg 